\title{
УРОВЕНЬ ГОМОЦИСТЕИНА У ПАЦИЕНТОВ ПРИ ОСЛОЖНЕННОМ И НЕОСЛОЖНЕННОМ ТЕЧЕНИИ ОСТРОГО КОРОНАРНОГО СИНДРОМА НА ФОНЕ СИНДРОМА НЕДИФФЕРЕНЦИРОВАННОЙ ДИСПЛАЗИИ СОЕДИНИТЕЛЬНОЙ ТКАНИ
}

\section{HOMOCYSTEINE LEVEL IN \\ PATIENTS WITH COMPLICATED AND UNCOMPLICATED COURSE OF ACUTE CORONARY SYNDROME AGAINST THE BACKGROUND OF UNDIFFERENTIATED CONNECTIVE TISSUE DYSPLASIA SYNDROME}

\section{O. Sultanova \\ E. Chernysheva \\ M. Kiseleva \\ B. Kuzmichev}

Summary. To study the level of homocysteine $(\mathrm{HC})$ in acute coronary syndrome (ACS) against the background of undifferentiated connective tissue dysplasia (UCTD), we examined 241 patients aged 35 to 65 years who were on inpatient treatment in the State Medical Institution of JSC Kirov State Clinical Hospital No. 3 and in the RSC AM Clinical Hospital. It was revealed that in patients with ACS on the background of UCTD, there is a statistically significant increase in the level of $\mathrm{HC}$ in blood plasma - $38.4 \mathrm{mmol} / \mathrm{l}$, compared with the control group and with patients with ACS without UCTD. The highest level of HC was registered in patients with complicated ACS on the background of SNDST - 41.5 $\mathrm{mmol} / \mathrm{l}$. It was found that in patients with ACS and UCTD, the increased content of $\mathrm{HC}$ was 4 times more common than in people without somatic pathology and was statistically significantly higher $(p<0.001)$.

Keywords: acute coronary syndrome, undifferentiated connective tissue dysplasia, homocysteine.

\section{Актуальность}

$\mathbf{K}$ ардиоваскулярная патология занимает лидирующие позиции среди причин, приводящих к смерти и инвалидности населения индустриально развитых стран $[20,27]$. При этом особый инте-
Султанова Оксана Эседуллаевна

Аспирант, ФГБОУ ВО «Астраханский государственный медицинский университет»

Минздрава России

oksanka.sultanova@mail.ru

Чернышева Елена Николаевна

Д.м.н., ФГБОУ ВО «Астраханский государственный медицинский университет» Минздрава России lena.chernysheva@inbox.ru

Киселева Мария Алексеевна

К.м.н., дочент, ФГБОУВО «Астраханский государственный медицинский университет» Минздрава России

kiseleva_m_a@mail.ru

Кузьмичев Богдан Юрьевич Ассистент, ФГБОУ ВО «Астраханский государственный медицинский университет»

Минздрава России bog13@list.ru

Аннотация. Для изучения уровня гомоцистеина (ГЦ) при остром коронарном синдроме (ОКС) на фоне синдрома недифференцированной дисплазии соединительной ткани (СНДСТ) нами был обследован 241 пациент В возрасте от 35 до 65 лет, находившийся на стационарном лечении в ГБУЗ АО ГКБ № 3 имени С.М. Кирова и в РСЦ АМОКБ. Выявлено, что у пациентов с ОКС на фоне СНДСТ имеет место статистически значимое повышение уровня ГЦ в плазме крови - 38,4 мкмоль/л, по сравнению с контрольной группой и с пациентами с ОКС без СНДСТ. Наибольший уровень ГЦ зарегистрирован у пациентов с осложненным течением ОКС на фоне СНДСТ 41,5 мкмоль/л. Установлено, что у пациентов с ОКС и СНДСТ повышенное содержание ГЦ встречалось в 4 раза чаще, чем у людей без соматической патологии и было статистически значимо выше $(p<0,001)$.

Ключевые слова: недифференцированная дисплазия соединительной ткани, острый коронарный синдром, гомоцистеин.

рес в структуре сердечно - сосудистых заболеваний вызывает ОКС [12]. По результатам независимого Российского Регистра Острого Коронарного Синдрома «РЕКОРД-3» (Российская Федерация, 2018 г.) частота смертельных исходов за 12 месяцев от развития ОКС составляла $15,8 \%$, а частота случаев смерти, резвив- 
шейся за год после выписки из стационара - 8,4\% [19, 24]. По литературным данным за последние 15 лет ОКС все чаще возникает у пациентов молодого возраста и имеет неблагоприятный прогноз $[2,3,18,17,15]$.

Неоспоримым является тот факт, что более чем в 90\% случаев ОКС развивается на фоне атеросклероза и есть состояния, которые могут приводить к раннему появлению атеросклеротических бляшек и развитию сердечно - сосудистых заболеваний, одним из которых является СНДСТ. У пациентов с дисплазией соединительной ткани выявлены структурные изменения коронарных сосудов [7, 22]. Кроме этого, Knowlman T. и соавторы установили, что у пациентов с ОКС и СНДСТ происходит активация тромбопоэза и изменения морфофункционального состояния тромбоцитов - они увеличены в размерах и высоко функционально активны (повышение скорости агрегации с коллагеном; увеличение поляризации клетки и оптической плотности), что приводит к повышенному тромбообразованию [28].

В литературе последних лет особый интерес направлен на поиск новых маркеров и факторов риска появления и прогрессирования сердечно-сосудистой патологии, одним из которых является ГЦ [5]. По значимости развития осложнений ГЦ можно сопоставить с гиперхолестеринемией и курением [11]. Высокий уровень ГЦ приводит к развитию цитотоксического эффекта - повреждение гладкомышечных клеток сосудов, что приводит к их сужению [14]. Гипергомоцистеинемия увеличивает риск развития атеросклероза, коронарной болезни сердца, поражения сосудов головного мозга, тромбоза коронарных, церебральных и периферических артерий, застойной сердечной недостаточности, фибрилляции предсердий, артериальной гипертензии $[6,10,21,23]$.

При этом, несмотря на достаточный объём исследований, проведённых в данном направлении, роль ГЦ остается не полностью изученной при ОКС на фоне СНДСТ, что обуславливает актуальность проведенного нами исследования.

\section{Цель исследования}

Изучить и проанализировать уровень гомоцистеина у пациентов при осложненном и неосложненном течении острого коронарного синдрома на фоне синдрома недифференцированной дисплазии соединительной ткани.

\section{Материалы и метолы}

Данное клиническое исследование и его дизайн были одобрены Региональным независимым этическим комитетом от 24.12.2020 г. № 2. Все участники предоставили письменные информированные согласия. Всего был обследован 241 пациент в возрасте от 35 до 65 лет, находившийся на стационарном лечении в ПСО городской клинической больницы № 3 имени С.М. Кирова и в региональном сосудистом центре Александро-Мариинской областной клинической больницы, которые были разделены на 3 группы: основная группа - 139 пациентов с ОКС на фоне СНДСТ: 86 мужчин (62\%) и 53 женщин (38\%) - медиана возраста составила 48 [43; 53] лет; группа сравнения - 102 пациента с ОКС без СНДСТ: 62 мужчины (67\%) и 34 женщины (33\%) - медиана возраста составила 54,0 [47; 59] года и группа контроля 50 соматически здоровых лиц: 30 мужчин (60\%) и 20 женщин (40\%) - медиана возраста составила 51,0 [45; 56] год. Группы пациентов, вошедших в исследование, были сопоставимы по возрасту и полу. Госпитализация пациентов осуществлялась в палату интенсивной терапии по службе скорой медицинской помощи во временной интервал от 60 минут до 24 часов (более поздние сроки поступления в стационар не входили в исследование). Далее диагноз инфаркта миокард и нестабильной стенокардии устанавливали на основании национальных рекомендаций Российского кардиологического общества $[12,13]$.

Уровень ГЦ в образцах плазмы определяли методом иммуноферментного анализа с помощью коммерческой тест системы «Axis Homocysteine» (каталожный номер FHCY100, фирма « Axis — shield Diagnostigs Ltd», (Великобритания), согласно прилагаемой к ней инструкции.

Статистический анализ результатов проводили на IBM с помощью пакета программ STATISTICA 12,0 («StatSoft», USA). В связи с тем, что было выявлено распределение данных отличное от нормального, применялись методы непараметрической статистики. Так, данные представлены в виде медианы (Ме) и 5-95 интерпроцентильных размахов. Для проведения межгрупповых сравнений в 3 и более группах использовался критерий Краскела - Уолиса, а при выявлении статистически значимых различий с целью проведения апостериорных сравнений применялся критерий U Манна - Уитни. Критерий $\chi^{2}$ Пирсона применялся для сравнения качественных данных. Уровень статистической значимости (p-value) составил $\mathrm{p}<0,05$.

\section{Результаты \\ и их обсужАение}

На первом этапе исследования мы изучили и проанализировали исходный уровень ГЦ у пациентов с ОКС на фоне СНДСТ, с ОКС без СНДСТ и у лиц контрольной группы (рисунок 1). 


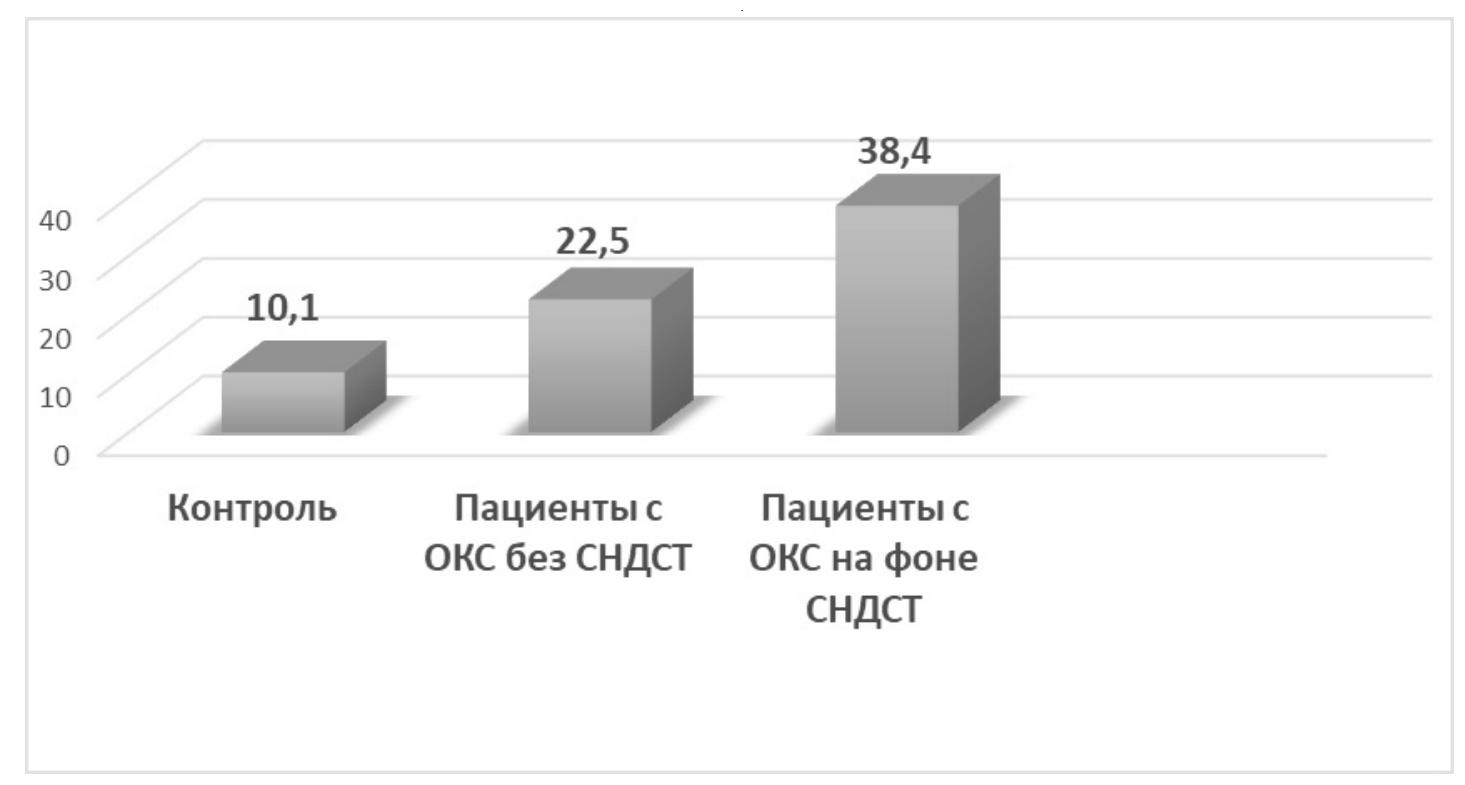

Рис. 1. Уровень гомоцистеина исследуемых группах (мкмоль/л)

Примечание: Значение критерия Краскела-Уоллиса $\mathrm{x}^{2}=161,763 ; d f=2 ; p<0,0001$.

Таблица 1. Уровень ГЦ у пациентов с ОКС без подъёма сегмента ST (OKСбпST) и с ОКС с подъёмом сегмента ST (OKCпST) в зависимости от наличия СНДСТ

\begin{tabular}{|c|c|c|c|c|}
\hline $\begin{array}{l}\text { Показатель / } \\
\text { Группа }\end{array}$ & $\begin{array}{l}\text { Группа пациентов } \\
\text { с ОКСбпSТ без СНДСТ, } \\
\text { n=40 }\end{array}$ & $\begin{array}{l}\text { Группа пациентов } \\
\text { с ОКСбпSТ на фоне } \\
\text { СНДСТ, n=39 }\end{array}$ & $\begin{array}{l}\text { Группа пациентов } \\
\text { с OKCпST без СНДСТ, } \\
\text { n=62 }\end{array}$ & $\begin{array}{l}\text { Группа пациентов } \\
\text { с ОKСпST на фоне } \\
\text { СНДСТ, } n=100\end{array}$ \\
\hline ГЦ, мКмОЛь/л & $\begin{array}{l}20,8 \\
{[13 ; 27,7]}\end{array}$ & $\begin{array}{l}28,3 \\
{[17,3 ; 39,8]} \\
\mathrm{p}_{1}<0,001\end{array}$ & $\begin{array}{l}25,7 \\
{[19,3 ; 32,1]} \\
p_{2}<0,001\end{array}$ & $\begin{array}{l}39,1 \\
{[23,7 ; 59,1]} \\
\mathrm{p}_{1}<0,001 \\
\mathrm{p}_{2}<0,001\end{array}$ \\
\hline
\end{tabular}

Примечание: $p_{1}$-уровень статистической значимости различий между группой пациентов с OКСбпST без СНДСТ с группой паџиентов с ОКСбпST на фоне СНДСТ и между группой паџиентов с OKCnST без СНДСТ с группой паџиентов с OKCnST на фоне СНДСТ; $p_{2}-$ уровень статистической значимости различий между группой паџчентов с ОКСбпST без СНДСТ с группой пациентов с ОКСnST без СНДСТ и между группой пациентов с OКСбпST на фоне СНДСТ с группой пацчентов с ОКСnST на фоне СНДСТ. Значение критерия Краскела-Уоллиса $\mathrm{x}^{2}=104,846 ; d f=3 ; p<0,0001$.

В группе контроля значении медианы уровня ГЦ составило 10,1 мкмоль/л при интерпроцентильных размaхах $[5,8 ; 14,1]$. В группе пациентов с ОКС без СНДСТ значение медианы уровня ГЦ составило 22,5 [13; 32,1] мкмоль/л, что было статистически значимо выше, чем в контрольной группе (p1<0,001). В группе пациентов с ОКС на фоне СНДСТ значение медианы уровня ГЦ составило 38,4 [17,3; 59,1] мкмоль/л, что было статистически значимо выше, как по сравнению с группой контроля (р1<0,001), так и по сравнению с группой пациентов с ОКС без СНДСТ (p2<0,001).

Таким образом, при сочетании ОКС и СНДСТ наблюдалось наибольшее повышение уровня ГЦ в плазме крови по сравнению, как с контрольной группой, так и с пациентами ОКС без СНДСТ.

Далее был проведен анализ уровня ГЦ у пациентов с OKC без подъёма сегмента ST (OKCбпST) и ОКС с подъёмом сегмента ST (OKCпST) в зависимости от наличия СНДСТ (таб.1).

В процессе статистического анализа полученных данных, нами установлено, что в группе пациентов с OKCбпST без СНДСТ значения медианы уровня ГЦ составило 20,8 мкмоль/л при интерпроцентильных размахах $[13 ; 27,7]$. В группе пациентов с OKCбпST на фоне СНДСТ значение медианы уровня ГЦ составило 28,3 
Таблица 2. Уровень ГЦ у пациентов при неосложненном и осложненном течении ОКС в зависимости от наличия СНДСТ

\begin{tabular}{|c|c|c|c|c|}
\hline $\begin{array}{l}\text { Показатель / } \\
\text { Группа }\end{array}$ & $\begin{array}{l}\text { Группа пациентов } \\
\text { с неосложненным } \\
\text { течением ОКС без СНДСТ, } \\
\text { n=71 }\end{array}$ & $\begin{array}{l}\text { Группа пациентов } \\
\text { с осложненным } \\
\text { течением ОКС без } \\
\text { СНДСТ, } n=31\end{array}$ & $\begin{array}{l}\text { Группа пациентов } \\
\text { с неосложненным } \\
\text { течением ОКС на фоне } \\
\text { СНДСТ, } \\
\text { n=55 }\end{array}$ & $\begin{array}{l}\text { Группа пациентов } \\
\text { с осложненным } \\
\text { течением ОКС на фоне } \\
\text { СНДСТ, n=84 }\end{array}$ \\
\hline ГЦ, мКмоль/л & $\begin{array}{l}20,3 \\
{[13 ; 27,5]}\end{array}$ & $\begin{array}{l}25,7 \\
{[19,4 ; 32,1]} \\
\mathrm{p}_{1}<0,001\end{array}$ & $\begin{array}{l}24,1 \\
{[17,3 ; 31,3]} \\
p_{2}<0,001\end{array}$ & $\begin{array}{l}41,5 \\
{[27,3 ; 59,1]} \\
p_{1}<0,001 \\
p_{3}<0,001\end{array}$ \\
\hline
\end{tabular}

Примечание: $p_{1}$ - уровень статистической значимости различий между группой пациентов с осложненным течением ОКС без СНДСТ с группой пациентов с неосложненньм течением

ОКС без СНДСТ и между группой пациентов с осложненным течением ОКС на фоне

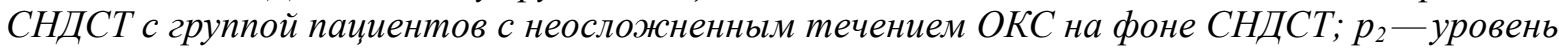
статистической значимости различий между группой пациентов с неосложненным течением ОКС на фоне СНДСТ с группой пациентов с неосложненным течением ОКС без

СНДСТ; $p_{3}$-уровень статистической значимости различий между группой пациентов с осложненным течением ОКС на фоне СНДСТ с группой пациентов с осложненным течением ОКС без СНДСТ. Значение критерия Краскела-Уоллиса $\mathrm{X}^{2}=151,947 ; d f=3 ; p<0,0001$.

[17,3; 39,8] мкмоль/л, что было статистически значимо выше, чем в группе пациентов с OKCбпST без СНДСТ ( $p<0,001)$. У пациентов в группе с OKCпST без СНДСТ значение медианы уровня ГЦ составило 25,7 мкмоль/л $[19,3 ; 32,1]$, что было статистически значимо выше по сравнению с группой пациентов с OKCбпST без СНДСТ ( $<<0,001)$. У пациентов в группе с OKCпST на фоне СНДСТ значение медианы уровня ГЦ составило $39,1[23,7 ; 59,1]$ мкмоль/л, что было статистически значимо выше, чем в группе пациентов с OKCпST без СНДСТ, и статистически значимо выше по сравнению с группой пациентов с ОКСбпST на фоне СНДСТ ( $<<0,001)$.

Исходя из полученных результатов становится очевидным, что наибольшее повышение уровня ГЦ наблюдалось у пациентов с OKCпST на фоне CHДСТ, что имело статистически значимые различия с пациентами остальных групп.

Нами были изучены и проанализированы уровни ГЦ у пациентов при осложненном и неосложненном течении ОКС в зависимости от наличия СНДСТ (таблица 2).

У пациентов с неосложненным течением ОКС без СНДСТ значение медианы уровня ГЦ составило 20,3 $[13 ; 27,5]$ мкмоль/л. В группе пациентов с осложненным течением ОКС без СНДСТ значение медианы уровня ГЦ составило 25,7 [19,4; 32,1] мкмоль/л, что было статистически значимо выше, чем в группе пациентов с неосложненным течением ОКС без СНДСТ ( $p<0,001)$. Значение медианы уровня ГЦ в группе пациентов с неосложненным течением ОКС на фоне СНДС составило 24,1 [17,3; 31,3] мкмоль/л, что было статистически зна- чимо выше по сравнению с группой пациентов с неосложненным течением ОКС без СНДСТ ( $p<0,001)$.

У пациентов с осложненным течением ОКС на фоне СНДСТ значение медианы уровня ГЦ составило 41,5 $[27,3 ; 59,1]$ мкмоль/л, что было статистически значимо выше, чем у пациентов с неосложненным течением ОКС без СНДСТ и также статистически значимо выше по сравнению с группой пациентов с осложненным течением ОКС без СНДСТ ( $p<0,001)$.

Таким образом, в группе пациентов с осложненным течением ОКС на фоне СНДСТ регистрировались самые высокие уровни ГЦ в плазме крови по сравнению с остальными группами пациентов.

\section{Выво $\triangle \mathrm{b}$}

1. Среди пациентов с ОКС на фоне СНДСТ уровень ГЦ имеет статистически значимо более высокое значение как по сравнению с группой контроля, так и с группой пациентов с ОКС без СНДСТ.

2. В группе пациентов с OKC на фоне CHДСТпST уровень ГЦ был статистически значимо выше по сравнению как с группой пациентов с ОКС на фоне СНДСТбпST, так и с группой пациентов с OKCпSТ без СНДСТ.

3. Среди всех обследуемых пациентов с осложненным течением ОКС уровень ГЦбыл статистически значимо выше, чем у пациентов с неосложненным течением ОКС. При этом, статистически значимо наиболее высокое значение уровня ГЦ у пациентов как с осложненным, так и с неосложненным течением ОКС на- 
блюдалось в группе пациентов с ОКС на фоне СНДСТ по сравнению с группой пациентов с ОКС без СНДСТ.

4. Мы полагаем, что выявленный наиболее высокий уровень ГЦ у пациентов с ОКС на фоне СНДСТ может быть обусловлен целым рядом патологических процессов и может свидетельствовать о перспективности и необходимости дальнейшего изучения уровня ГЦ как предиктора развития осложненного течения ОКС как на фоне СНДСТ, так и без СНДСТ.

\section{ЛИТЕРАТУРА}

1. Аксенов С.И. Структурные изменения коронарных сосудов у пациентов с дисплазией соединительной ткани (кросс-секционное наблюдение) [Текст] / С.И. Аксенов Е.А. Лялюкова, Г.И. Нечаева, Ю.Т. Игнатьев // Лечащий врач. — 2016.— № 2.— С. 27-30.

2. Андреенко Е.Ю. Ишемическая болезнь сердца у лиц молодого возраста: распространенность и сердечно-сосудистые факторы риска [Текст] / Е.Ю. Андреенко, И.С. Явелов, М.М. Лукьянов, А.Н. Вернохаева, 0.М. Драпкина, С.А. Бойцов // Кардиологи. — 2018. — Т. 58, № 11.— С. 24-34.

3. Барбаш 0.Л. Особенности клинического течения и стационарного этапа лечения пациентов с острым коронарным синдромом с подъемом сегмента ST в зависимости от пола (по данным Российского Регистра Острого коронарного синдрома «Рекорд-3» / 0.Л. Барбаш [и др.] // Российский кардиологический журнал. — 2017. - № 6 (146).—C. 122-131.

4. Васина Л.В. Эндотелиальная дисфункция и ее основные маркеры [Текст] / Л.В. Васина, Н.Н. Петрищев, Т.Д. Власов // Регионарное кровообращение и микроциркуляция. - 2017. - Т. 16, № 1.- С. 4-15.

5. Давыдчик Э.В. Взаимосвязь гипергомоцистеинемии с ишемической болезнью сердца и сахарным диабетом / Э.В. Давыдчик, В.А. Снежицкий, Л.В. Никонова // Журнал Гродненского государственного медицинского университета. - 2015.— № 1. С. 9-13.

6. Денисова А.Г. Гипергомоцистеинемия и дисфункция эндотелия артерий в оценке риска сердечно-сосудистых осложнений у больных сахарным диабетом / А.Г. Денисова, И.П. Татарченко, Н.В. Позднякова, Е.Р. Кулюцина, О.А. Левашова // Здоровье и образование в XXI веке. 2016. Т. 18, № 2. С. 25-29.

7. Друк И.В. Состояние коронарных артерий при дисплазиях соединительной ткани [Текст] / Г.И. Нечаева, В.В. Кузнецова // Казанский медицинский журнал.— 2007.- - Т. 88, № 5, приложение.- С. 30-32.

8. Ефимов В.С. Гипергомоцистеинемия в клинической практике: руководство [Текст] // В.С. Ефимов и др — М.: ГЕОТАР-Медиа, 2013. - 79 с.

9. Елыкомовой В.А, Копыловой А.Н. Способ диагностики дисплазии соединительной ткани. Патент на изобретение № 2665387 Р.Ф. / Заявл. 04.05.2017; опубл. 29.08.2018.

10. Зотова Д.А. Роль гомоцистеина в патогенезе некоторых заболеваний / Д.А. Зотова, С.А. Козлов // Известия высших учебных заведений. Поволжский регион. Медицинские науки. — 2016. — № 3 (39).— - С. 132-144.

11. Каражанова Л.К. Гипергомоцистеинемия как фактор риска сердечно-сосудистые заболевания (обзор литературы) / Л.К. Каражанова, А.С. Жунуспекова // Наука и здравоохранение (Казахстан). 2016. № 4. С. 129-144.

12. Клинические рекомендации Министерства здравоохранения Российской Федерации «0стрый коронарный синдром без подъёма сегмента ST электрокардиограммы» [Текст] / Российское кардиологическое общество при участии ассоциации сердечно-сосудистых хирургов России // — 2020.— C. $12-25$

13. Клинические рекомендации Министерства здравоохранения Российской Федерации «Острый коронарный синдром с подъёмом сегмента ST электрокардиограммы» [Текст] / Российское кардиологическое общество при участии ассоциации сердечно-сосудистых хирургов России // - 2020. - С. 18-22.

14. Кузьмичев Б.Ю. Исследование уровня гомоцистеина у пациентов с инфарктом миокарда на фоне хронической обструктивной болезни легких [Текст] / Б.Ю. Кузьмичев, Е.А. Полунина, К.Ю. Кузьмичев, Е.А. Липницкая, М.С. Аджян // Астраханский медицинский журнал.— 2017.— Т. 12, № 4. — С. 44-50.

15. Ложкина Н.Г. Многофакторное прогнозирование отдаленных исходов острого коронарного синдрома со стойким подъемом сегмента ST [Текст] / Е.А. Глебченко, М.Х. Хасанова, В.Н. Максимов, А.Д. Куимов, Ю.И. Рагино, М.И. Воевода // Российский кардиологический журнал.— 2015.— № 9.— C. $25-31$.

16. Мадиева М.Р. Клинико-эпидемиологическое значение синдрома дисплазии соединительной ткани в формировании врожденных пороков сердца [Текст] / М.Р. Мадиева, Т.Х. Рымбаева // Наука и Здравоохранения. — 2017.— № 4. — C. 94-112.

17. Мирошникова Е.П. Особенности течения и лечения инфаркта миокарда у больных с признаками дисплазии соединительной ткани [Текст]: автореф. дис. На соискание научной степени кандидата медицинских наук (2020) / Елизавета Петровна Мирошникова: Крымский Федеральный университет имени В.И. Вернадского. - Симферополь, 2020. - 148с.

18. Оганов Р.Г. Сосудистая коморбидность: общие подходы к профилактике и лечению [Текст] / Р.Г. Оганов // Рациональная фармакотерапия в кардиологии. - 2015. Т. 11, № 1.- С. 4-7.

19. Округин С.А. Программа В03 «Регистр острого инфаркта миокарда»: эпидемиологический мониторинг острых коронарных катастроф [Текст] / С.А. Округин, Е.А. Кужелева, А.А. Гарганеева // Комплексные проблемы сердечно-сосудистых заболеваний. — 2018. — № 7(1). — C. 76-83.

20. Перепеч Н.Б. Острый коронарный синдром: патогенез, диагностика, лечение, реабилитация [Текст] / Н.Б. Перепеч // Лекторий практического врача. - 2016. - Т. 7, № 1.—C. 70-81.

21. Снежицкий В.А. Гомоцистеин как прогностический маркер предсердного ремоделирования и клинического течения у пациентов с пароксизмальной и персистирующей формами фибрилляции предсердий / В.А. Снежицкий, Е.С. Яцкевич, Е.М. Дорошенко, В.Ю. Смирнов, Т.С. Долгошей, А.Ю. Рубинский // Клиническая медицина. 2016. № 1 (94). С. 16-22. 
22. Султанова 0.Э. Анатомические особенности коронарных сосудов у пациентов с острым коронарным синдромом на фоне синдрома недифференцированной дисплазии соединительной [Текст] / 0.Э. Султанова, Е.Н. Чернышева //Актуальные вопросы современной медицины. Материалы IV Международной научно-практической конференции Прикаспийских государств. Астрахань: Издательство Астраханского ГМУ, 2019 г.- С. 160-162.

23. Султанова 0.Э. Эволюция тренда исследований гомоцистеина в кардиологической практике [Текст] / 0.Э. Султанова, Е.Н. Чернышева, А.В. Коханов, И.В. Севостьянова // Современные проблемы науки и образования. — 2020. — № 4.; URL: http://science-education.ru/ru/article/view?id=29937 (дата обращения: 21.11.2020).

24. Эрлих А.Д. 12-месячные исходы у пациентов с острым коронарным синдромом, включенных в Российский Регистр Рекорд-3 [Текст] / А.Д. Эрлих // Российский кардиологический журнал. - 2018. - № 3 (155). - С. 23-30.

25. Hemradj V.V. Cardiogenic Shock Predicts Longterm Mortality in Hospital Survivors of STEMI Treated With Primary Percutaneous Coronary Intervention [Text] / V.V. Hemradj, J.P Ottervanger, A.W van't Hof [et al.]. // Clin. Cardiol._ 2016._ - Vol.39. — P. 4

26. Hu G., Zhang J., Tian Y.G., Li Y.H., You L., Qiao L.J. Diagnostic value of joint detection of homocysteine and RDW CV on acute miocardial infarction // Eur. Rev. Med. Pharmacol. Sci. 2016. Vol. 20, № 19. P. 4124-4128.

27. Ibanez B. Guidelines for the management of acute myocardial infarctionin patients presenting with ST-segment elevation. The Task Force for the management of acute myocardial infarction in patients presenting with ST-segment elevation of the European Society of Cardiology (ESC) [Text] / B. Ibanez [et al.] // European Heart Journal. - 2018. - Vol. 39.- P. 119-177.

28. Knowlman, T. The association of electrocardiographic abnormalities and major adverse cardiac events in emergency patients with chest pain [Text] / T. Knowlman, J.H. Greenslade., W. Parsonage [et al.] // Acad. Emerg. Med. — 2017 -Vol.19. — P. 1-4.

29. Li Y., Zhou Y., Zhang Y., Zhang J. Admission homocysteine is an independend predictor of spontaneous reperfusion and early infarct-related artery patency before primary percutaneous coronary intervention in ST-segment elevation miocardial infarction // BMC Cardiovascular Disorders. 2018. Vol. 18, № 1. P. 125.

30. Marković B.M., Čaušević A., Brizić l., Mikulić l., Vasily M., Knezović N.J. A relation of serum homocysteine, uric acid and C-reactive protein level in patients with acute miocardial infarction // Medicinski Glasnik. 2018. Vol. 15, № 2. P. 101-108.

31. Zhang S., Zhang S., Wang H., Wu W., Ye Y. Arginine methylation dysfunction increased risk of acute coronary syndrome in coronary artery disease population // Medicine. 2017. Vol. 96, no. 7.

( С Султанова Оксана Эседуллаевна ( oksanka.sultanova@mail.ru ), Чернышева Елена Николаевна ( lena.chernysheva@inbox.ru ), Киселева Мария Алексеевна ( kiseleva_m_а@mail.ru ), Кузьмичев Богдан Юрьевич ( bog13@list.ru ).

Журнал «Современная наука: актуальные проблемы теории и практики»

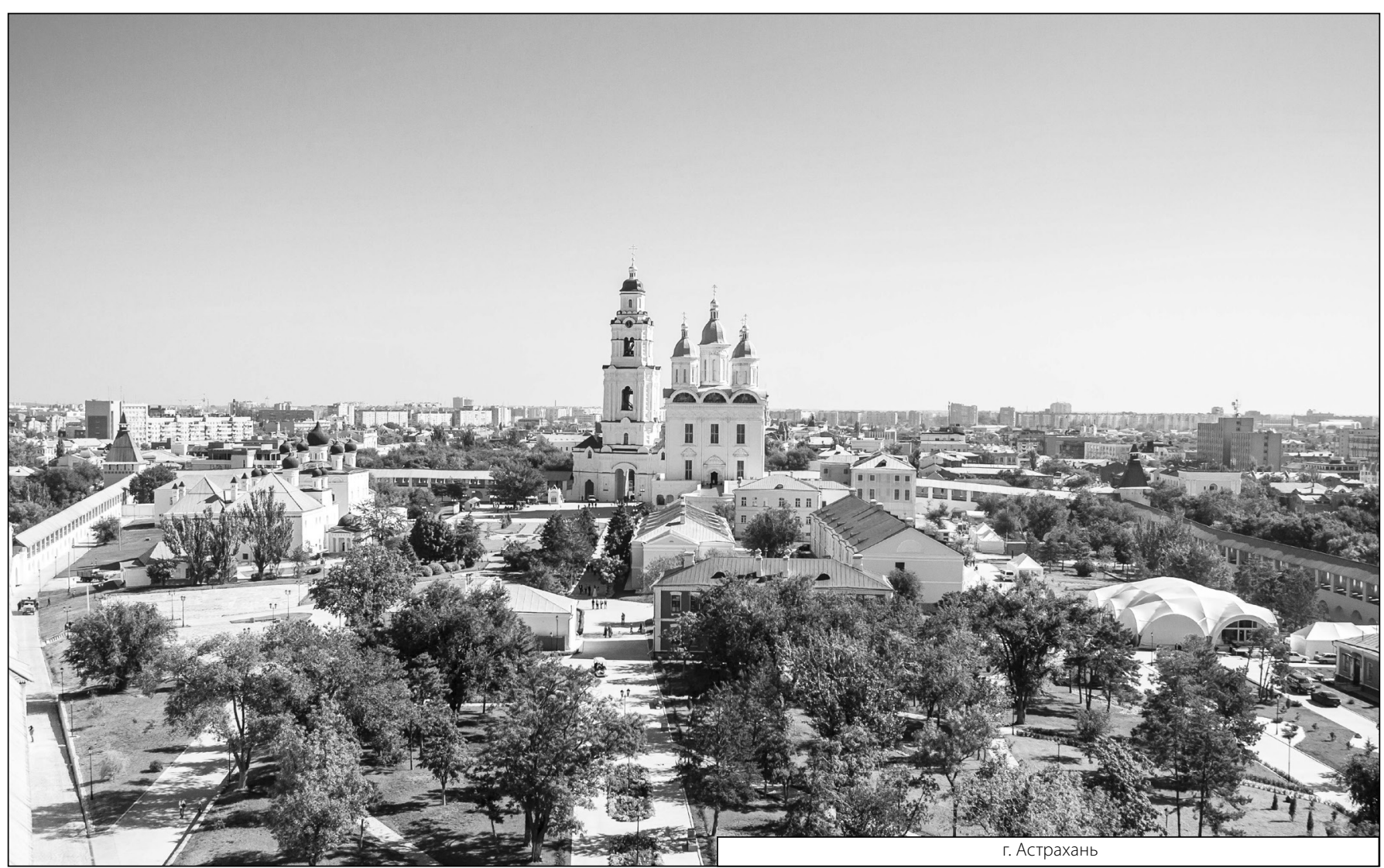

